\title{
EMPREGO DE CINZAS RESIDUAIS DA QUEIMA EM CALDEIRAS NA ADSORÇÃO DE CORANTES REATIVOS
}

\author{
F. B. SCHEUFELE ${ }^{1}$, C. RIBEIRO ${ }^{1}$, K. C. KERBER ${ }^{1 *}$, W. A. ROMANZINI ${ }^{1}$, C. E. BORBA ${ }^{1}$, \\ APARECIDO N. MÓDENES ${ }^{1}$ \\ ${ }^{1}$ Universidade Estadual do Oeste do Paraná, Departamento de Engenharia Química \\ *e-mail: kennedykerber@hotmail.com
}

\begin{abstract}
RESUMO
Este trabalho consistiu na avaliação do desempenho da cinza de eucalipto residual de caldeira na remoção de corante azul reativo 5G. Tratamentos químicos foram realizados no adsorvente visando aumentar sua capacidade de adsorção, pelos quais obteve-se uma melhoria de aproximadamente $50 \%$ pelo tratamento com $\mathrm{H}_{2} \mathrm{O}_{2} 5 \%$ (v/v). Na avaliação dos parâmetros operacionais sobre o processo adsortivo como: $\mathrm{pH}$, temperatura de adsorção, tempo, e velocidade de agitação empregou-se um delineamento composto central rotacional (DCCR). Por meio do planejamento experimental obtiveram-se as melhores condições operacionais utilizando-se a metodologia de superfície de resposta: $\mathrm{pH} 2,0$, temperatura de $30^{\circ} \mathrm{C}$ e velocidade de agitação de $150 \mathrm{rpm}$. Na avaliação da cinética do processo, obteve-se um tempo de equilíbrio de aproximadamente 24 horas, sendo que o modelo de pseudo-segunda ordem melhor se ajustou aos dados experimentais. Além disso, avaliou-se a possibilidade de difusão intrapartícula pelo modelo de Weber e Morris, no qual verificou-se que a etapa de transferência de massa que controla o processo é a adsorção nos sítios. Finalmente, a isoterma de Langmuir representou os dados de equilíbrio adequadamente, apresentando uma capacidade máxima de adsorção de $46,6 \mathrm{mg} \mathrm{g}^{-1}$ e um coeficiente de afinidade $0,0245 \mathrm{~L} \mathrm{mg}^{-1}$. Os resultados obtidos no estudo sugerem que a cinza possui potencial para emprego como material adsorvente na remoção de efluentes contendo corantes têxteis em solução.
\end{abstract}

\section{INTRODUÇÃO}

O constante crescimento das atividades industriais tem provocado inúmeros problemas ambientais, oriundos dos dejetos e efluentes lançados, poluindo e degradando ecossistemas. Dentre esses dejetos e efluentes, encontram-se os corantes sintéticos, oriundos em sua grande maioria dos processos em indústrias têxteis, as quais apresentam um elevado volume de rejeitos além de uma grande variação na composição de seus efluentes (VANDEVIVERE, BIANCHI \& VERSTRAETE, 1998).
Em sua maioria, os efluentes têxteis quando despejados em corpos de águas proporcionam um aspecto desagradável e cor, e não atendendo as legislações vigentes, necessitam de tratamento (VIJAYARAGHAVAN \& YUN, 2008). Os corantes têxteis são em sua grande maioria compostos orgânicos tóxicos e altamente resistentes à degradação. Possuem estruturas moleculares aromáticas, formadas por hidrocarbonetos tais como benzeno, naftaleno, antraceno, tolueno e xileno (GONG et al., 2006).

A remoção dos corantes é dificultosa, devido à sua estrutura complexa e estável. 
Além disso, também há uma vasta gama de tipos de corantes como: ácidos, básicos, dispersos, reativos azo e diazo e corantes de complexos de metais, o que torna seu tratamento muito específico (ROBINSON et al., 2001). Os corantes reativos são mais difundidos no setor têxtil. São tóxicos e mutagênicos, carcinogênicos e teratogênicos, possuem alta solubilidade, desta forma afetam diretamente a biota marinha e o seu ambiente quando descartados indevidamente (SADHASIVAM, SAVITHA \& SWAMINATHAN, 2007).

Diversos métodos de tratamento têm sido aplicados neste tipo de efluente, sendo que os mais recentemente aplicados são coagulação/ floculação (LIANG et al., 2014), flotação (ZODI et al., 2013), eletrocoagulação (PALÁCIO et al., 2009), processos oxidativos avançados (MÓDENES et al., 2012) e adsorção (FIORENTIN et al., 2010).

Pesquisas vêm mostrando que a adsorção com carvão ativado apresenta grande capacidade de remoção de diversos tipos de corantes. No entanto, o carvão ativado apresenta um elevado custo de produção (GUPTA \& SUHAS, 2009), incentivando a procura de novos adsorventes com um menor valor agregado, a fim de tornar o processo viável. Cinzas residuais da queima do eucalipto em caldeiras são um resíduo abundante e sem destinação adequada, já que são amplamente utilizadas como fonte combustível no setor industrial (MALL, SRIVASTAVA \& AGARWAL, 2006).

Neste sentido, este trabalho teve como objetivo principal avaliar possibilidade do emprego de cinzas residuais de eucalipto na remoção do corante reativo Azul 5G. Para isto, foram realizados: (i) tratamentos químicos no material focando o aumento do potencial adsortivo; (ii) avaliação dos parâmetros operacionais do processo; (iii) estudo da cinética e equilíbrio de adsorção.

\section{MATERIAIS E MÉTODOS}

\subsection{Materiais}

$\mathrm{O}$ adsorvente utilizado foi a cinza de eucalipto residual de caldeiras, fornecida pela BRF, Toledo - PR. O efluente sintético foi preparado com corante Azul 5G, com 815 g mol $^{-1}$, produzido e doado pela Texpal Industria Química S/A, de Valinhos - SP. Preparou-se uma solução estoque de $1000 \mathrm{mg} \mathrm{L}^{-1}$, na qual o pH inicial das soluções de corante foi ajustado utilizando $\mathrm{HCl}$ e $\mathrm{NaOH} 1 \mathrm{M}$.

\subsection{Tratamentos do adsorvente}

Visando aumentar a capacidade de adsorção de adsorvente, foram realizados tratamentos químicos na cinza in natura, utilizando agentes ativantes ácidos, alcalinos, oxidativa e combinados. Realizou-se o tratamento do adsorvente com soluções ácidas de $\mathrm{HCl} 0,1 \mathrm{M}$ e $1 \mathrm{M}$ e alcalinas com $\mathrm{NaOH}$ $0,01,0,1,1,2$ e $3 \mathrm{M}$, na proporção $20 \mathrm{~g}$ de cinza para $1 \mathrm{~L}$ de solução, sendo mantida a $80^{\circ} \mathrm{C}$ por 30 minutos sob agitação. Após decantar, retirou-se o excesso da solução, sendo posteriormente seca a $105^{\circ} \mathrm{C}$ em estufa com convecção forçada até estabilização da massa.

Outro tratamento empregado nas cinzas in natura foi com peróxido de hidrogênio. Neste tratamento as seguintes porcentagens foram utilizadas: $0,1,1,5,10,20$ e $30 \%(\mathrm{v} / \mathrm{v})$ de $\mathrm{H}_{2} \mathrm{O}_{2}$. Foram adicionados $30 \mathrm{~mL}$ das soluções de peróxido em frascos Erlenmeyer de $125 \mathrm{~mL}$ contendo $10 \mathrm{~g}$ de cinza, sendo mantidos em uma mesa agitadora orbital (Marconi e MA-420) a $150 \mathrm{rpm}$ e $30^{\circ} \mathrm{C}$ por 24 h. Após esse período a cinza foi retirada e seca em uma estufa convectiva.

Realizou-se, ainda, uma combinação entre o tratamento básico e com peróxido de hidrogênio, nesta ordem, na tentativa de obter melhores resultados.

\subsection{Procedimento Experimental}

Os ensaios de adsorção do corante reativo Azul 5G pela cinza de eucalipto foram realizados em sistema fechado e batelada, em 
duplicata. Para isto, frascos Erlenmeyer de 125 $\mathrm{mL}$ contendo $50 \mathrm{~mL}$ de solução do corante e $0,1 \mathrm{~g}$ do adsorvente foram mantidos sob agitação (50 a $150 \mathrm{rpm}$ ), em mesa agitadora orbital com controle de temperatura (20 a $40^{\circ} \mathrm{C}$ ), conforme a matriz do planejamento experimental. Em intervalos de tempo prédeterminados (2 a 46 h), os frascos Erlenmeyer foram retirados. A solução aquosa com corante remanescente foi separada do adsorvente por centrifugação (5 min a $3000 \mathrm{rpm}$ ). A concentração de corante na fase líquida foi determinada por espectrofotometria UV-vis (Shimadzu UV 1800), no comprimento de máxima absorbância característico do corante $(620 \mathrm{~nm})$ (FIORENTIN et al., 2010).

A quantidade de corante adsorvida foi calculada pelo balanço de massa conforme a Equação 1.

$$
q=\frac{V\left(C_{0}-C\right)}{m}
$$

Em que: $q\left(\mathrm{mg} \mathrm{g}^{-1}\right)$ é a quantidade de corante adsorvida por unidade de massa de adsorvente; $C_{0}$ e $C\left(\mathrm{mg} \mathrm{L}^{-1}\right)$ são as concentrações inicias e finais do corante nas soluções, respectivamente; $V(\mathrm{~mL})$ é o volume da solução de corante e $m$ (g) a massa de adsorvente.

\subsection{Planejamento experimental}

Visando avaliar os efeitos dos parâmetros operacionais: agitação, da temperatura, tempo e $\mathrm{pH}$, bem como suas possíveis interações sobre o processo de adsorção, foi realizado um delineamento composto central rotacional (DCCR), avaliando-se como variável resposta a capacidade de remoção do adsorvente. Os níveis empregados para cada variável são apresentados na Tabela 1.

A metodologia de superfície de resposta foi utilizada para determinar as melhores condições para, posteriormente, efetuar os experimentos cinéticos e de equilíbrio de adsorção. $\mathrm{Na}$ análise dos resultados obtidos utilizou-se o software STATISTICA $^{\text {TM }}$ (versão 8.0 da StatSoft, Inc.), sendo gerada uma tabela de efeitos para avaliar a influência das variáveis e de suas interações sobre a resposta, considerando o nível de significância de $5 \%$.

Tabela 1. Especificação dos níveis das variáveis avaliadas no planejamento DCCR na adsorção em cinza de eucalipto.

\begin{tabular}{cccccc}
\hline \multirow{2}{*}{ Variáveis } & \multicolumn{5}{c}{ Níveis } \\
\cline { 2 - 6 } & $\mathbf{( - 2 )}$ & $\mathbf{( - 1 )}$ & $\mathbf{0}$ & $\mathbf{( + 1 )}$ & $\mathbf{( + 2 )}$ \\
\hline $\mathrm{pH}$ & 2 & 4 & 6 & 8 & 10 \\
$\mathrm{t}(\mathrm{h})$ & 2 & 13 & 24 & 35 & 46 \\
$\mathrm{w}(\mathrm{rpm})$ & 50 & 75 & 100 & 125 & 150 \\
$\mathrm{~T}\left({ }^{\circ} \mathrm{C}\right)$ & 20 & 25 & 30 & 35 & 40 \\
\hline
\end{tabular}

\section{RESULTADOS E DISCUSSÃO}

\subsection{Tratamentos químicos}

Os melhores resultados dos tratamentos para as diferentes concentrações de cada um dos tipos de agente ativante empregados são apresentados na Figura 1.

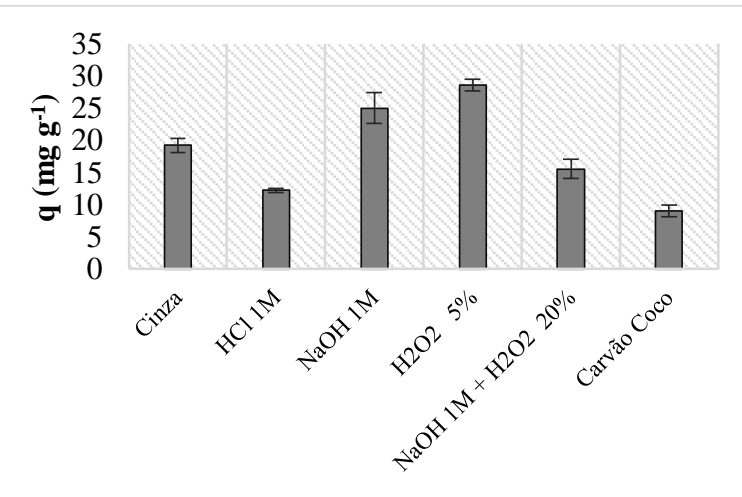

Figura 1. Capacidade de remoção do corante reativo Azul $5 \mathrm{G}$ em função dos tratamentos químicos do adsorvente.

Como podemos observar dentre os tratamentos avaliados, o com hidróxido de sódio $1 \mathrm{M}$ e peróxido de hidrogênio $5 \%$ apresentaram aumentos na remoção do corante de 30 e $49 \%$, respectivamente. Ao passo que os agentes ativantes ácidos e combinado 
diminuíram a capacidade de adsorção da cinza in natura. Desta forma, os experimentos de adsorção posteriores utilizaram a cinza tratada com peróxido $5 \%$.

\subsection{Testes preliminares}

Na Tabela 2, observa-se a matriz do planejamento DCCR, com as variáveis nas suas formas codificadas e seus valores reais.

Tabela 2. Matriz do planejamento DCCR com valores das variáveis do processo e de resposta.

\begin{tabular}{|c|c|c|c|c|c|}
\hline \multirow{2}{*}{ Ensaio } & \multicolumn{4}{|c|}{ Variáveis } & \multirow{2}{*}{$\begin{array}{l}\text { Resposta } \\
\text { q(mg/g) }\end{array}$} \\
\hline & pH & $\mathbf{T}\left({ }^{\circ} \mathbf{C}\right)$ & w (rpm) & $\mathbf{t}(\mathbf{h})$ & \\
\hline 1 & $-1(4)$ & $-1(25)$ & $-1(75)$ & $-1(13)$ & 10,003 \\
\hline 2 & $+1(8)$ & $-1(25)$ & $-1(75)$ & $-1(13)$ & 1,846 \\
\hline 3 & $-1(4)$ & $+1(35)$ & $-1(75)$ & $-1(13)$ & 11,849 \\
\hline 4 & $+1(8)$ & $+1(35)$ & $-1(75)$ & $-1(13)$ & 6,406 \\
\hline 5 & $-1(4)$ & $-1(25)$ & $+1(125)$ & $-1(13)$ & 10,763 \\
\hline 6 & $+1(8)$ & $-1(25)$ & $+1(125)$ & $-1(13)$ & 6,555 \\
\hline 7 & $-1(4)$ & $+1(35)$ & $+1(125)$ & $-1(13)$ & 12,310 \\
\hline 8 & $+1(8)$ & $+1(35)$ & $+1(125)$ & $-1(13)$ & 6,759 \\
\hline 9 & $-1(4)$ & $-1(25)$ & $-1(75)$ & $+1(35)$ & 10,261 \\
\hline 10 & $+1(8)$ & $-1(25)$ & $-1(75)$ & $+1(35)$ & 6,990 \\
\hline 11 & $-1(4)$ & $+1(35)$ & $-1(75)$ & $+1(35)$ & 11,414 \\
\hline 12 & $+1(8)$ & $+1(35)$ & $-1(75)$ & $+1(35)$ & 5,999 \\
\hline 13 & $-1(4)$ & $-1(25)$ & $+1(125)$ & $+1(35)$ & 11,346 \\
\hline 14 & $+1(8)$ & $-1(25)$ & $+1(125)$ & $+1(35)$ & 6,908 \\
\hline 15 & $-1(4)$ & $+1(35)$ & $+1(125)$ & $+1(35)$ & 12,324 \\
\hline 16 & $+1(8)$ & $+1(35)$ & $+1(125)$ & $+1(35)$ & 6,338 \\
\hline 17 & $-2(2)$ & $0(30)$ & $0(100)$ & $0(24)$ & 24,362 \\
\hline 18 & $+2(10)$ & $0(30)$ & $0(100)$ & $0(24)$ & 7,261 \\
\hline 19 & $0(6)$ & $-2(20)$ & $0(100)$ & $0(24)$ & 3,352 \\
\hline 20 & $0(6)$ & $+2(40)$ & $0(100)$ & $0(24)$ & 4,940 \\
\hline 21 & $0(6)$ & $0(30)$ & $-2(50)$ & $0(24)$ & 5,293 \\
\hline 22 & $0(6)$ & $0(30)$ & $+2(150)$ & $0(24)$ & 5,565 \\
\hline 23 & $0(6)$ & $0(30)$ & $0(100)$ & $-2(2)$ & 5,809 \\
\hline 24 & $0(6)$ & $0(30)$ & $0(100)$ & $+2(46)$ & 6,053 \\
\hline 25 & $0(6)$ & $0(30)$ & $0(100)$ & $0(24)$ & 5,958 \\
\hline 26 & $0(6)$ & $0(30)$ & $0(100)$ & $0(24)$ & 7,030 \\
\hline 27 & $0(6)$ & $0(30)$ & $0(100)$ & $0(24)$ & 5,483 \\
\hline 28 & $0(6)$ & $0(30)$ & $0(100)$ & $0(24)$ & 3,990 \\
\hline
\end{tabular}

A resposta obtida á a quantidade de corante adsorvido por grama de cinza $q$. Neste planejamento foi realizada uma quadruplicata no ponto central, afim de verificar a reprodutibilidade dos dados experimentais. Observa-se que o Ensaio 17 ( $\mathrm{pH}$ 2, temperatura $30^{\circ} \mathrm{C}$, velocidade de agitação $100 \mathrm{rpm}$ e tempo $24 \mathrm{~h}$ ) apresentou maior capacidade de adsorção do corante reativo Azul 5G $\left(q=24,36 \mathrm{mg} \mathrm{g}^{-1}\right)$. A partir dos dados apresentados na Tabela 2 elaborou-se a tabela de efeitos (conforme Tabela 3), na qual verifica-se que apenas o parâmetro $\mathrm{pH}$, tanto o termo linear (L) quanto o quadrático $(\mathrm{Q})$, são significativos $(\mathrm{p}<0,05)$, para as condições avaliadas. Os demais parâmetros e suas interações não apresentaram resultados significativos, para um intervalo de confiança de $95 \%$. Considerando-se o valor negativo do coeficiente linear do $\mathrm{pH}$ verificase que em menores valores de $\mathrm{pH}$ deve-se esperar maiores taxas de remoção do corante. Este resultado concorda com o melhor resultado experimental obtido no $\mathrm{pH} 2$.

Tabela 3. Estimativa dos efeitos do planejamento DCCR para a adsorção do corante $5 \mathrm{G}$ em cinza residual de eucalipto.

\begin{tabular}{cccc}
\hline & p-valor & Coeficiente & Erro \\
\hline Intercepto & 0,000 & 5,846 & 0,721 \\
$\boldsymbol{p} \boldsymbol{H}(\boldsymbol{L})$ & $\mathbf{0 , 0 0 0}$ & $\mathbf{- 3 , 4 2 0}$ & $\mathbf{0 , 2 9 4}$ \\
$\boldsymbol{p} \boldsymbol{H}(\boldsymbol{Q})$ & $\mathbf{0 , 0 0 0}$ & $\mathbf{2 , 1 3 6}$ & $\mathbf{0 , 2 9 4}$ \\
T (L) & 0,834 & 0,062 & 0,294 \\
T (Q) & 0,455 & $-0,222$ & 0,294 \\
w (L) & 0,120 & 0,467 & 0,294 \\
w(Q) & 0,181 & 0,401 & 0,294 \\
t (L) & 0,418 & 0,241 & 0,294 \\
t (Q) & 0,582 & 0,163 & 0,294 \\
pH x T & 0,914 & $-0,039$ & 0,360 \\
pH x w & 0,569 & $-0,207$ & 0,360 \\
pH x t & 0,765 & $-0,109$ & 0,360 \\
T x w & 0,974 & 0,012 & 0,360 \\
T x t & 0,907 & 0,042 & 0,360 \\
w x t & 0,948 & $-0,024$ & 0,360 \\
\hline
\end{tabular}

Elaboraram-se ainda as superfícies de resposta para a capacidade de adsorção da cinza em função dos parâmetros operacionais em pares, mantendo-se os outros fixados nos seus respectivos pontos centrais, as quais são apresentadas nas Figuras 2 e 3. Na Figura 2 
nota-se que os maiores valores de remoção de corante $(q)$ são obtidos para baixos valores de pH e agitações da ordem de 150 rpm. É notável a influência do $\mathrm{pH}$ sobre a remoção do corante, ao passo que a velocidade de agitação influencia positivamente $o$ processo, no entanto numa intensidade consideravelmente menor.

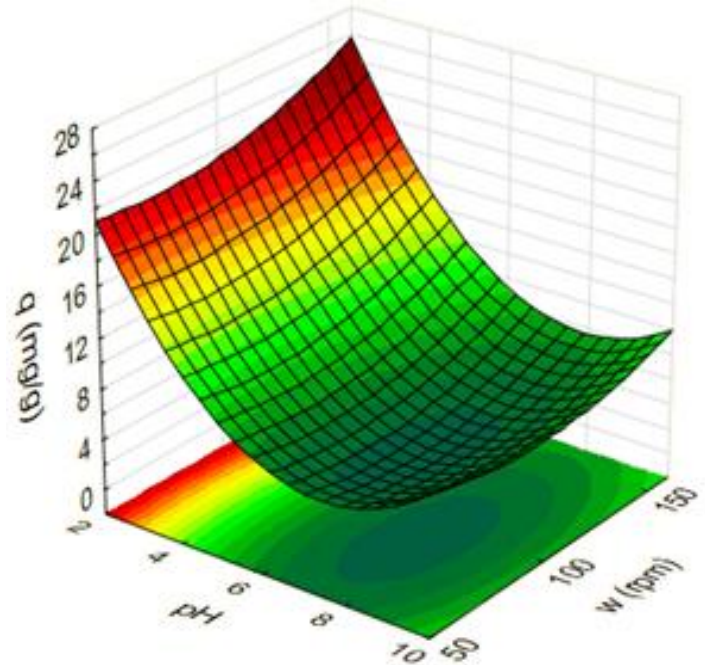

Figura 2. Superfície de resposta da capacidade de remoção de corante reativo Azul $5 \mathrm{G}$ pela cinza residual de eucalipto em função do pH e w (rpm) $\left(\mathrm{T}=30^{\circ} \mathrm{C}\right.$ e $\left.\mathrm{t}=24 \mathrm{~h}\right)$.

Observando-se a Figura 3 nota-se que tanto a temperatura quanto o tempo de adsorção não aumentam significativamente a remoção do corante na faixa estudada. Desta forma, nota-se apenas um pequeno aumento na capacidade de adsorção para a temperatura em torno de $30^{\circ} \mathrm{C}$ e uma leve inclinação favorecendo tempos de contato entre adsorvente e o adsorbato acima de 24 horas. Considerando que a variável tempo não apresentou-se como significativa, observa-se que mesmo nos menores tempos avaliados no planejamento o processo encontra-se praticamente no equilíbrio, visto que não existem variações significativas da remoção do corante.

Desta forma, verifica-se que as melhores condições operacionais para a adsorção do corante reativo Azul 5G pelas cinzas residuais de eucalipto são: $\mathrm{pH}$ 2, velocidade de agitação $150 \mathrm{rpm}$, temperatura de $30^{\circ} \mathrm{C}$.

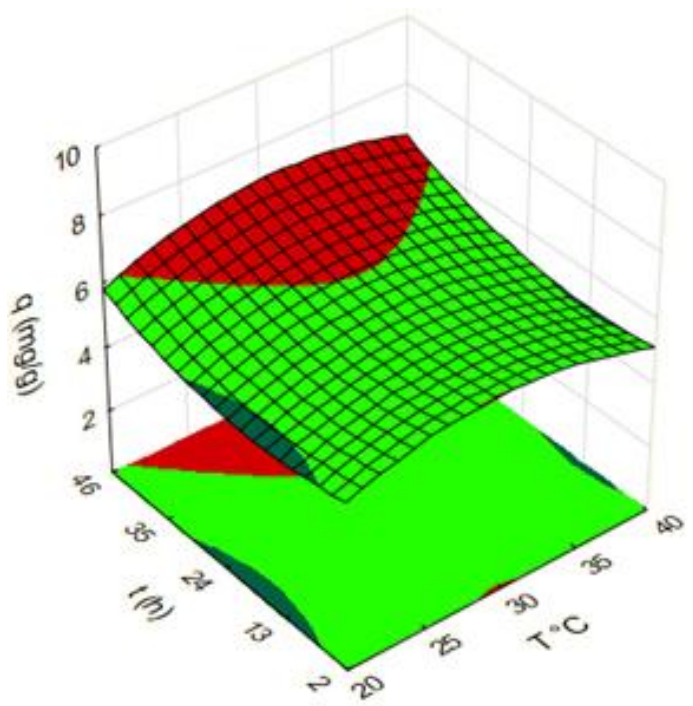

Figura 3. Superfície de resposta da capacidade de remoção de corante $5 \mathrm{G}$ pela cinza residual de eucalipto em função do tempo (h) e $\mathrm{T}\left({ }^{\circ} \mathrm{C}\right)(\mathrm{pH}=6$, $\mathrm{W}=100 \mathrm{rpm})$.

\subsection{Cinética de adsorção}

Determinadas as condições ótimas pelos testes preliminares realizaram-se os experimentos cinéticos nestas condições. A cinética de adsorção do corante reativo Azul 5G é a apresentada na Figura 4, juntamente com o ajuste dos modelos cinéticos aos dados experimentais obtidos. Os modelos analisados foram $\mathrm{o}$ de pseudo-primeira ordem (LAGERGREN, 1898) e pseudo-segunda ordem (HO \& MCKAY, 1998). Os parâmetros dos modelos foram obtidos pelo método Levenberg-Marquardt utilizando-se o software Origin ${ }^{\circledR} 8.0$, e se seus respectivos valores são apresentados na Tabela 5.

Pelos valores do coeficiente de correlação, verifica-se que o modelo de pseudo-segunda ordem apresentou o melhor ajuste aos dados experimentais. Estes resultados sugerem que o processo adsortivo é de natureza química e que o mesmo controla o processo (HO \& MCKAY, 1998). 
Tabela 5. Parâmetros estimados dos modelos cinéticos aos dados experimentais de cinética de adsorção do corante reativo Azul 5G pela cinza residual de eucalipto.

\begin{tabular}{lcc}
\hline \multicolumn{1}{c}{ Equação } & Parâmetro & Valor \\
\hline $\begin{array}{l}\text { Pseudo-primeira } \\
\text { ordem }\end{array}$ & $K_{l}\left(\mathrm{~min}^{-1}\right)$ & $119,36 \pm 16,9$ \\
$\frac{d q(t)}{d t}$ & $q_{e q}\left(\mathrm{mg} \mathrm{g}^{-1}\right)$ & $21,64 \pm 0,50$ \\
$=k_{1}\left[q_{e}-q(t)\right]$ & $r^{2}$ & 0,893 \\
Pseudo-segunda & $K_{2}\left(\mathrm{~g} \mathrm{mg}^{-1} \mathrm{~min}^{-1}\right)$ & $9,11 \pm 1,08$ \\
ordem & $q_{e q}\left(\mathrm{mg} \mathrm{g}^{-1}\right)$ & $22,42 \pm 0,30$ \\
$\frac{d q(t)}{d t}$ & $r^{2}$ & 0,969 \\
$=k_{2}\left[q_{e}-q(t)\right]^{2}$ & & \\
\hline
\end{tabular}

Além disso, o processo de adsorção do corante reativo Azul 5G pelas cinzas residuais de eucalipto apresentou uma cinética extremamente favorável, sendo que a maior parte da remoção do corante ocorreu em menos de $60 \mathrm{~min}$. No entanto, de uma maneira geral é possível afirmar que o tempo de equilíbrio é atingido em torno de $24 \mathrm{~h}$ de processo.

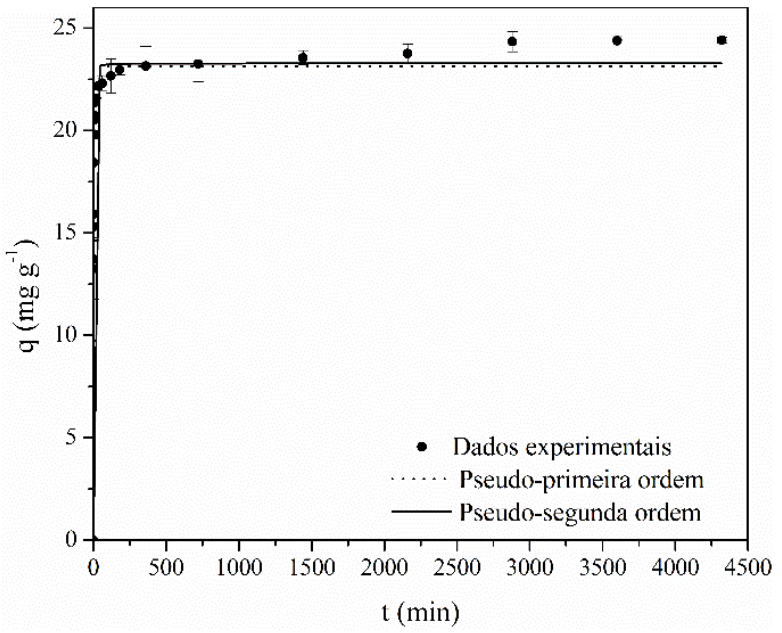

Figura 4. Cinética de adsorção do corante reativo Azul 5G pelas cinzas residuais de eucalipto.

Com o objetivo de aprofundar a avaliação dos mecanismos de transferência de massa no processo de adsorção avaliou-se a resistência de transferência de massa devido à difusão intrapartícula. Para isto, empregou-se o modelo proposto por Weber \& Morris (1963), conforme a Equação (2).

$$
q(t)=k_{d i f} \sqrt{t}+C
$$

Em que, $k_{\text {dif }}$ é a constante da difusão intrapartícula $\left(\mathrm{mg} \mathrm{g}^{-1} \mathrm{~min}^{-1 / 2}\right), C$ é a constante relacionada com a espessura da camada limite de difusão ( $\left.\mathrm{mg} \mathrm{g}^{-1}\right)$ e $t$ é o tempo (min).

O gráfico da capacidade de adsorção do corante versus a raiz quadrada do tempo é apresentado na Figura 5, no qual é possível notar três regiões distintas. A primeira região $\left(0<\mathrm{t}^{1 / 2}<2,5\right)$ corresponde à resistência a transferência de massa externa, ou seja, no seio da fase líquida. Observa-se que esta etapa é muito rápida, não apresentando resistências difusionais significativas ao processo global de adsorção. Além disso, a segunda região (2,5 < $\left.\mathrm{t}^{1 / 2}<13,5\right)$ pode ser atribuída à resistência interna, na estrutura porosa do adsorvente. Esta etapa apresentou uma inclinação menos elevada que a etapa anterior $\left(k_{d i f, 2}=0,147 \mathrm{mg}\right.$ $\mathrm{g}^{-1} \mathrm{~h}^{-1 / 2}$ - Tabela 6), indicando que esta etapa é mais lenta que a anterior. Posteriormente, uma terceira região $\left(13,5<\mathrm{t}^{1 / 2}<53,6\right)$ pode ser relacionada com a adsorção do corante nos sítios ativos do material adsorvente. Observase que esta etapa é notavelmente mais lenta que as demais.

Tabela 6. Parâmetros do modelo cinético de Weber \& Morris.

\begin{tabular}{ccc}
\hline Região & Parâmetros & Valores \\
\hline & $k_{d i f, I}\left(\mathrm{mg} \mathrm{g}^{-1} \mathrm{~h}^{-1 / 2}\right)$ & $10,634 \pm$ \\
I & $r^{2}$ & 1,057 \\
& & 0,958 \\
& $k_{d i f, 2}\left(\mathrm{mg} \mathrm{g}^{-1} \mathrm{~h}^{-1 / 2}\right)$ & $0,147 \pm 0,015$ \\
II & $C_{2}\left(\mathrm{mg} \mathrm{g}^{-1}\right)$ & $21,089 \pm$ \\
& $r^{2}$ & 0,119 \\
& & 0,974 \\
III & $k_{d i f, 3}\left(\mathrm{mg} \mathrm{g}^{-1} \mathrm{~h}^{-1 / 2}\right)$ & $0,030 \pm 0,004$ \\
& $C_{3}\left(\mathrm{mg} \mathrm{g}^{-1}\right)$ & $22,514 \pm$ \\
& $r^{2}$ & 0,153 \\
& & 0,963 \\
\hline
\end{tabular}

Portanto, a etapa de adsorção nos sítios controla o processo global de adsorção do corante reativo Azul 5G nas cinzas residuais de 
eucalipto (WEBER \& MORRIS, 1963). Este resultado corrobora com o melhor ajuste observado pelo modelo cinético de pseudosegunda ordem. Finalmente, após 53,6 $\mathrm{min}^{1 / 2} \mathrm{o}$ processo entra em equilíbrio.

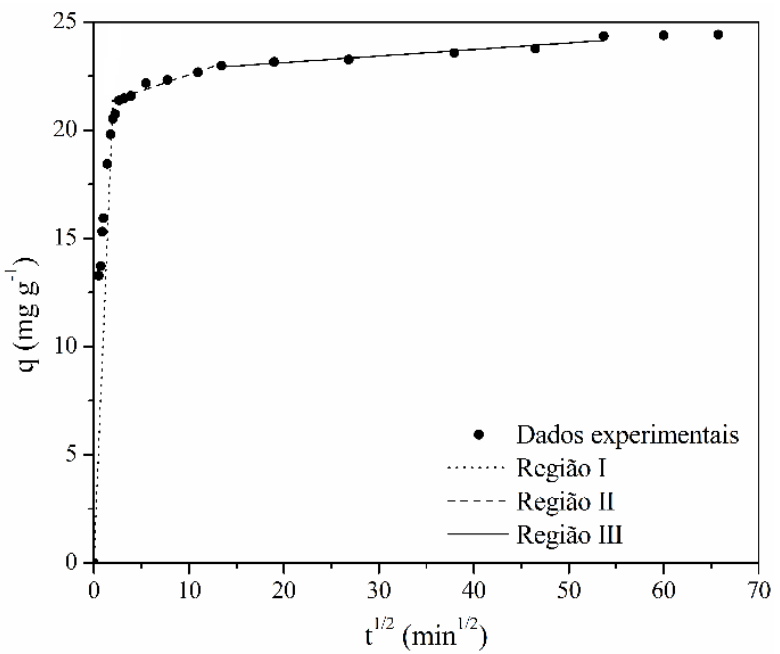

Figura 5. Modelo cinético de Weber \& Morris para a adsorção do corante reativo Azul $5 \mathrm{G}$ pelas cinzas residuais de eucalipto.

\subsection{Isoterma de adsorção}

Após a determinação do tempo de equilíbrio, obtiveram-se os dados de equilíbrio de adsorção do corante reativo Azul 5G pela cinza residual de eucalipto, conforme a Figura 6. Na descrição dos dados experimentais empregaram-se os modelos de Langmuir, Freundlich e Sips. Os parâmetros dos modelos foram obtidos com auxílio do software Origin 8.0, pelo método Levenberg-Marquardt. Os valores dos parâmetros estimados são apresentados na Tabela 7.

Avaliando-se os coeficientes de correlação apresentados, observa-se que o modelo que melhor representou os dados de equilíbrio foi o de Langmuir, o qual assume que a capacidade máxima de adsorção corresponde à saturação dos sítios, formandose uma monocamada de moléculas de soluto na superfície do adsorvente (LANGMUIR, 1918). Neste sistema, obteve-se uma capacidade máxima de adsorção de $45,602 \mathrm{mg} \mathrm{g}^{-1}$ e um coeficiente de afinidade igual a $0,0245 \mathrm{~L} \mathrm{mg}^{-1}$.

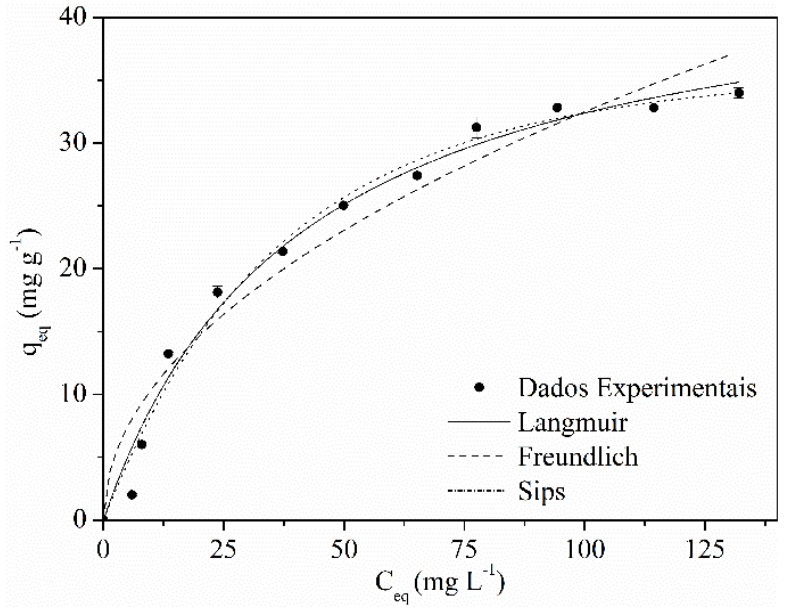

Figura 6. Ajustes das isotermas aos dados de equilíbrio de adsorção do corante reativo Azul 5G pelas cinza residuais de eucalipto.

Tabela 7. Parâmetros estimados das isotermas de adsorção do corante reativo Azul 5G pela cinza residual de eucalipto.

\begin{tabular}{lcc}
\hline \multicolumn{1}{c}{ Modelo } & Parâmetros & Valores \\
\hline Langmuir $(1918)$ & $q_{\max }\left(\mathrm{mg} \mathrm{g}^{-1}\right)$ & $45,602 \pm 2,678$ \\
$q=\frac{q_{\max } b C_{e q}}{1+b C_{e q}}$ & $b\left(\mathrm{~L} \mathrm{mg}^{-1}\right)$ & $0,0245 \pm 0,004$ \\
Freundlich $(1906)$ & $r^{2}$ & 0,983 \\
$q=k\left(\mathrm{mg} \mathrm{g}^{-1}\right)$ & $3,332 \pm 0,083$ \\
& $n$ & $2,022 \pm 0,235$ \\
Sips $(1948)$ & $r^{2}$ & 0,946 \\
$q=\frac{q_{\max }\left(K_{S} C_{e q}\right)^{n}}{1+\left(K_{S} C_{e q}\right)^{n}}$ & $q_{\max }\left(\mathrm{mg} \mathrm{g}^{-1}\right)$ & $45,602 \pm 2,678$ \\
& $n$ & $0,0245 \pm 0,004$ \\
& $r^{2}$ & $1 \pm 0,18$ \\
& &
\end{tabular}

Ainda é possível observar que o modelo de Sips apresentou um $r^{2}$ igual ao de Langmuir. Além disso, o valor do expoente estimado de Sips apresentou valor unitário $(n=1)$, indicando um sistema homogêneo, fazendo com que o modelo se reduza ao de Langmuir (SIPS, 1948).

Os resultados de cinética e equilíbrio de adsorção do corante reativo Azul 5G pelas cinzas residuais de eucalipto mostraram uma cinética rápida de remoção deste poluente e uma capacidade de adsorção expressiva. Desta forma, considerando-se a proveniência 
residuária e o fato de não haver uma destinação adequada ou outras formas de aproveitamento na indústria, torna este material como uma alternativa na remoção de efluentes têxteis contendo corantes em solução.

\section{CONCLUSÕES}

Foi possível aumentar a capacidade de adsorção da cinza residual de eucalipto com tratamento com peróxido de hidrogênio $(5 \%)$. Além disso, por meio do planejamento experimental foi possível identificar os parâmetros operacionais significativos e, consequentemente, as melhores condições $(\mathrm{pH}$ 2,0, temperatura de $30^{\circ} \mathrm{C}$ e velocidade de agitação de $150 \mathrm{rpm}$ ) pela metodologia de superfície de resposta no planejamento DCCR. Os experimentos cinéticos indicaram um processo favorável, sendo que em apenas três minutos já atinge-se $81 \%$ de sua capacidade máxima de adsorção para o corante reativo Azul 5G, mostrando que o processo é rápido. Dentre os modelos avaliados, o de pseudosegunda ordem melhor representou os dados cinéticos, indicando um processo com natureza química. Além disso, o modelo de difusão intrapartícula, indicou que as etapas difusivas exercem pouca influência na cinética do processo e a adsorção nos sítios é a etapa controladora do processo. Os dados de equilíbrio foram representados pela isoterma de Langmuir, indicando um sistema homogêneo e adsorção em monocamada. Os dados de equilíbrio alcançaram uma capacidade de adsorção expressiva tratando-se de um adsorvente residuário $\left(q_{\max }=45,602 \mathrm{mg}\right.$ $\left.\mathrm{g}^{-1}\right)$.

De uma maneira geral, os resultados indicam que a cinza residual de eucalipto residual de caldeira poderia ser empregada como um adsorvente alternativo para $\mathrm{o}$ tratamento de efluentes contendo corantes têxteis em solução, principalmente por apresentar uma cinética de adsorção rápida e não possuir baixo valor agregado e nenhuma destinação adequada.

\section{REFERENNCIAS}

FIORENTIN, L. D., TRIGUEROS, D. E. G., MÓDENES, A. N., ESPINOZA-QUIÑONES, F. R., PEREIRA, N. C., BARROS, S. T. D., SANTOS, O. A. A. Biosorption of reactive blue $5 \mathrm{G}$ dye onto drying orange bagasse in batch system: Kinetic and equilibrium modeling. Chemical Engineering Journal, v.163, p. 68-77, 2010.

FREUNDLICH H. Over the adsorption in solution (Uber die adsorption in Lusungen). Journal of Physical Chemistry (Zeitschrift fur Physikalische Chemie), v.57, p.385-470, 1906.

GONG, R., ZHANG, X., LIU, H., SUN, Y., LIU, B. Uptake of cationic dyes from aqueous solu-tion by biosorption onto granular kohlrabi peel. Bioresource Technology, v. 98, p. 1319-1323, 2007.

GUPTA, V. K. \& SUHAS, Application of low-cost adsorbents for dye removal - A review. Journal of Environmental Management, v. 90 p.2313-2342, (2009).

HO, I. S., MCKAY, G. A comparison of chemisorption kinetic models applied to pollutant removal on various sorbents. Trans IChemE, v. 76, p. 332-340, 1998.

LAGERGREN, S. About the theory of socalled adsorption of soluble substances. Kungliga Suensk Vetenskapsakademiens Handlingar, v.4, 1-39, 1898.

LANGMUIR, I. The adsorption of gases on plane surfaces of glass, mica and platinum. Journal of the American Chemical Society, v.40, n.9, p.1361-1403, 1918. 
LIANG, C., SUN, S., LI, F., ONG, Y., CHUNG, T. Treatment of highly concentrated wastewater containing multiple synthetic dyes by a combined process of coagulation/flocculation and nanofiltration, Journal of Membrane Science, v. 469, p.306-315, 2014.

MALL, I.D., SRIVASTAVA, V.C., AGARWAL, N.K. Removal of Orange-G and Methyl Violet dyes by adsorption onto bagasse fly ash - kinetic study and equilibrium isotherm analyses. Dyes and Pigments, v.69, p.210-223, 2006.

MÓDENES, A. N., ESPINOZA-QUIÑONES, F. R., BORBA, F. H., MANENTI, D. R. Performance evaluation of an integrated photo-Fenton - Electrocoagulation process applied to pollutant removal from tannery effluent in batch system. Chemical Engineering Journal v. 197, p. 1-9, 2012.

PALÁCIO, S. M., ESPINOZA-QUIÑONES, F. R., MÓDENES, A. N., OLIVEIRA, C. C., BORBA, F. H., SILVA JR., F. G. Toxicity assessment from electrocoagulation treatedtextile dye wastewaters by bioassays. Journal of Hazardous Materials, v. 172, p. 330-337, 2009.

ROBINSON, T., MCMULLAN, G., MARCHANT, R., NIGAM, P., Remediation of dyes in textile effluent: a critical review on current treatment technologies with a proposed alternative. Bioresource Technology, v. 77, p. 247-255, 2001.

SADHASIVAM, S., SAVITHA, S., SWAMINATHAN, K. Exploitation of Trichoderma harzianum mycelia waste for the removal of rhodamine $6 \mathrm{G}$ from aqueous solution. Journal of Environmental Management, v. 85, p. 155-161, 2007.
SIPS, R. Combined form of Langmuir and Freundlich equations. Journal of Chemical Physics, v.16, p. 490-495, 1948.

VANDEVIVERE, P. C., BIANCHI, R., VERSTRAETE, $W$. Treatment and reuse of Wastewater from the textile wetprocessing industry: review of emerging technologies. Journal of Chemical Technology \& Biotechnology. v.72, p. 289-302, 1998.

VIJAYARAGHAVAN K., YUN Y. Bacterial biosorbents and biosorption. Biotechnology Advances. v.26 p.266-291, 2008.

WEBER, W.J., MORRIS, J.C. Kinetics of adsorption on carbon from solution. Journal of the Sanitary Engineering Division, v.89, p.31-60, 1963. S.

ZODI, S., MERZOUK, B., POTIER, O., LAPICQUE, F., LECLERC, J. Direct red 81 dye removal by a continuous flow electrocoagulation/flotation reactor. Separation and Purification Technology, v. 108, p.215-22, 2013.

\section{AGRADECIMENTOS}

À BRF pelo fornecimento das cinzas de eucalipto residuais, à Texpal Indústria Química S/A pelo corante e a CAPES pelo financiamento da pesquisa. 